\title{
LOS CLÁSICOS ESPAÑOLES \\ DEL DERECHO NATURAL \\ Y LA REHABILITACIÓN \\ DE LA RAZÓN PRÁCTICA
}

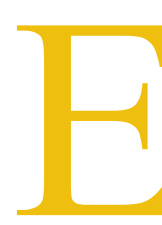

1 tiempo de los iusnaturalistas clásicos españoles fue época de profundas transformaciones y cambios, de novedades y descubrimientos en el pensamiento y la existencia, que presenta grandes analogías con la nuestra. No es difícil trazar un paralelismo entre lo que supusieron los descubrimientos geográficos, a su vez, producto de descubrimientos técnicos como la brújula y la carabela, o la invención de la imprenta en la conformación del Renacimiento; y las implicaciones del descubrimiento de la energía atómica, la exploración del espacio y las nuevas tecnologías de la información y la comunicación para el orto de la actual «sociedad informatizada». Esas correlaciones no son sólo externas, su principal afinidad radica en la reproducción de determinadas actitudes vitales. Se ha aludido al asombro, inquietud y esfuerzo intelectual de quienes tuvieron que asumir el encuentro de América sin contar con categorías previas en las que alojarlo ${ }^{1}$. De forma similar el ciudadano de las sociedades tecnológicamente avanzadas del presente siente que se ha producido un paulatino extrañamiento respecto a su entorno natural y cultural. Las nuevas tecnologías nos asombran con una sucesión de inventos, anteriormente insospechados, que hacen que vaya perdiendo su dimensión sobrehumana la realización de actividades inalcanzables para las generaciones precedentes. El hombre actual puede asistir sin desplazarse a lo que ocurre a miles de kilómetros, ha establecido redes comunicativas a escala planetaria y tiene acceso a ingentes stocks de información perfectamente organizada en bancos de datos. Estas profundas transformaciones determinan que los individuos y los grupos de las sociedades informatizadas se sientan sobrecogidos

${ }^{1}$ E. Tierno Galván, «La angustia del tiempo y del espacio, fundamento de la Conquista de América», en Revista de Estudios Políticos, 1949, n. ${ }^{\circ}$ 47, pp. 152 ss. 
ante ese ambiente artificial cuyas reglas de funcionamiento, las más de las veces, desconocen ${ }^{2}$.

En la década de los setenta, de forma casi simultánea, aparecieron en Alemania dos importantes obras colectivas respectivamente referidas a la «rehabilitación de la Filosofía práctica $»^{3}$ y la «Teoría constructiva de la ciencia y la Filosofía práctica» ${ }^{4}$. La primera había sido compilada por Manfred Riedel y la segunda por Friedrich Kambartel y fueron proseguidas por un estudio monográfico de Rüdiger Bubner, en cuyo título significativamente se alude al «renacimiento de la Filosofía práctica» ${ }^{5}$. El interés por la Filosofía práctica que estos trabajos estaban denunciando no puede considerarse casual, sino fruto de las aporías y urgencias de nuestra época. Desde los inicios del siglo actual se advierte una progresiva inclinación de los filósofos a reflexionar sobre cuestiones prácticas. En el período que media entre las dos Guerras Mundiales y, de forma especial, tras el final de la segunda, que dejó tras sí la consciencia universal de los más siniestros crímenes contra la humanidad, cobró mayor urgencia la atención hacia las cuestiones nodales que definen la vida social. Ahora, en la medida en que se empiezan a advertir las implicaciones planetarias de los riesgos de las nuevas tecnologías, se acrecienta el interés de los individuos y las colectividades más responsables por evaluar el impacto del progreso científico-técnico desde patrones éticos adecuados.

Los cauces filosóficos expresivos de esas inquietudes han sido múltiples y heterogéneos. Sin pretensión alguna de exhaustividad cabe aludir a la decantación hacia la «filosofia della pratica» del neoidealismo a través de Benedetto Croce, cuya alternativa marxista representada por Antonio Gramsci fue la «filosofia della prassi». La Filosofía práctica gozó también de amplio consenso en el mundo anglosajón en las diferentes versiones del «pragmatismo»; e incluso el giro analítico desde los lenguajes científicos a los lenguajes usuales reforzó la atención hacia la práctica. El existencialismo y el raciovitalismo

${ }^{2} \mathrm{Cfr}$. mi libro, Nuevas tecnologías, sociedad y derecho. El impacto socio-jurídico de las N. T. de la información, Fundesco, Madrid, 1987. 1.972-74.

${ }^{3}$ M. Riedel, Rehabilitierung der praktischen Philosophie, 2 vols., Rombach, Freiburg i. B.,

${ }^{4}$ F. Kambartel, Praktische Philosophie und konstruktive Wissenschaftstheorie, Suhrkamp, Frankfurt a.M., 1974. Existe trad. cast. de E. Garzón Valdés, con el título, Filosofía práctica y teoría constructiva de la ciencia, Alfa, Buenos Aires, 1978.

${ }^{5}$ R. Bubner, «Eine Renaissance der praktischen Philosophie», en Philosophische Rundschau, 1975, n. $^{\circ} 1-2$, pp. 1 ss. 
orteguiano situaron la actividad práctica en el propio núcleo de su reflexión. En los últimos años la Escuela de Frankfurt, la Ética dialógica y las diversas teorías sobre la argumentación no han hecho sino consolidar ese proceso rehabilitador del pensamiento práctico.

El influjo de estas orientaciones en el pensamiento jurídico ha sido profundo y extenso. Dar cuenta pormenorizada de las posturas teóricas desde las que se expresa la incidencia de la razón práctica en el Derecho equivaldría a hacer inventario de la mayor parte de las concepciones de la Filosofía y la Teoría jurídica del presente. Para evitar el desbordamiento del objeto de esta reflexión, bastará la escueta referencia a algunos de los empeños doctrinales de mayor notoriedad actual.

Pionero en la restauración del interés jurídico por la racionalidad práctica fue Theodor Viehweg, quien concibe la «tópica» como el método dialógico que orienta el razonamiento jurídico hacia la decisión de los casos, o problemas concretos, en los que se expresa el Derecho ${ }^{6}$. Deben también mencionarse los estudios sobre la nueva retórica debidos a Chairri Perelman, tendentes a mostrar la estructura argumentativa del razonamiento jurídico ${ }^{7}$; así como la revalorización de la razón práctica, denominada por Luis Recaséns Siches «logos de lo razonable», en la interpretación y aplicación del Derecho ${ }^{8}$.

La relevancia general de la racionalidad práctica en los sistemas normativos ha sido objeto de un estudio de Joseph Raz, en el que concibe las «razones» (reasons) como relaciones entre hechos y personas, siempre que se trate de hechos con proyección normativa en cuanto que determinen la actuación debida. Raz más que de la filosofía práctica valorativa, tendente a mostrar los valores que deben perseguirse y las razones orientadoras de la acción, prefiere centrar su atención en el análisis práctico conceptual de categorías tales como la del valor, norma, acción y de la naturaleza de las reglas de inferencia que gobiernan el razonamiento práctico. Para ello propugna una filosofía general de la razón práctica, que estudiaría conceptos comunes a las diversas disciplinas prácticas (derecho, moral y política), tales como los de regla y sistema normativo. Corolario de tal premisa es su convicción de que es posible y necesario desarrollar una lógica unificada de los conceptos

${ }^{6}$ Th. Viehweg, Topik und Jurisprudenz, Beck, München, 1953. (De esta obra existe trad. cast. de L. Díez-Picazo, Tópica y jurisprudencia, Taurus, Madrid, 1964).

${ }^{7}$ Ch. Perelman, Traité de l'argumentation. La nouvelle rhétorique, en col. con L. Olbrechts-Tyteca, Editions de l'Université de Bruxelles, Bruxelles, 1970.

${ }^{8}$ L. Recaséns Siches, Experiencia jurídica, naturaleza de la cosa y Lógica «razonable», Fondo de Cultura Económica \& UNAM, México, 1971. 
normativos, y que la parte básica de esa lógica no es la lógica deóntica, sino la lógica de las razones para la acción'.

En el marco de tales inquietudes es también digno de mención el esfuerzo de Robert Alexy por sugerir reglas y procedimientos tendentes a garantizar la racionalidad de la argumentación jurídica. Se pretende evitar, de este modo, que las ineludibles valoraciones del jurista intérprete degeneren en juicios de valor subjetivos y arbitrarios. La referencia a las normas materiales y procesales aplicables al caso, la obligada consideración de los precedentes, así como las pautas orientadoras de la Dogmática jurídica institucionalmente cultivada, constituyen el horizonte en el que se proyecta la racionalidad práctica en el Derecho $^{10}$. Josef Esser hace referencia a la necesidad de que el jurista intérprete tenga presentes las expectativas de la colectividad para que el resultado de la función hermenéutica, que posee una insoslayable dimensión práctica, goce de un amplio consenso social $^{11}$. John Hart Ely insistirá, a su vez, en la necesidad de que la decisión judicial se vea limitada por la exigencia de ponderar los intereses de los afectados, sobre la base de una consideración igual de sus personas ${ }^{12}$.

En estos últimos años la teoría de Ronald Dworkin ha supuesto una revalorización de la racionalidad práctica como parámetro orientador de la interpretación jurídica, que se evidencia en el requerimiento de que el juez se atenga a los standards o conceptos morales generales y básicos de la sociedad. El juez, ante la insuficiencia de la norma legal no puede crear normas, sino que debe recurrir a principios que expresan esos standards ético-políticos institucionalizados que son el soporte legitimador de las Constituciones democráticas. La teoría jurídica tiene como una de sus principales funciones la de clarificar el sentido y alcance de esa moralidad institucional. La Dogmática contribuye así a que el juez al decidir en base a principios, que expresan valores morales, disponga de pautas doctrinales de

${ }^{9}$ J. Raz, Practical Reason and Norms, Hutchinson, Londres, 1975. (De la segunda edición de esta obra que data de 1990 existe trad. cast. de J. Ruiz Manero, Centro de Estudios Constitucionales, Madrid, 1991).

${ }^{10}$ R. Alexy, Theorie der juristischen Argumentation, Suhrkamp, Frankfurt a.M., 1978. (Trad. cast. de M. Atienza e I. Espejo, Teoría de la argumentación jurídica, Centro de Estudios Constitucionales, Madrid, 1990). Cfr. M. Atienza, Las razones del Derecho. Teorías de la argumentación jurídica, Centro de Estudios Constitucionales, Madrid, 1991, pp. 177 ss.

${ }^{11} \mathrm{~J}$. Esser, Vorverständnis und Metodhenwahl in der Rechtsfindung, Atheneum, Frankfurt a.M., 1970.

${ }^{12}$ J. Hart Ely, Democracy and Distrust. A theory of Judicial Review, Harvard University Press, Cambridge (Mass.) y Londres, 1980. 
fundamentación racional que le auxilien en su decisión y prevengan, a la postre, la incerteza del Derecho ${ }^{13}$.

En la dimensión institucional de las pautas de racionalidad práctica de la función judicial han hecho especial hincapié Neil MacCormick y Ota Weinberger. Los sistemas jurídicos contemporáneos requieren un alto grado de racionalidad tanto en su estructura normativa como en los procedimientos de aplicación del Derecho. La racionalidad práctica desempeña una importante función de garantía de la adecuación de las decisiones judiciales a consecuencias socialmente deseables y racionalmente fundadas. Mediante el ejercicio de la racionalidad práctica los jueces tienden a apoyar sus decisiones en criterios universalizables; es decir, rebasan objetivos particulares para perseguir aquellos valores generalizados e institucionalizados en la práctica social, que legitiman la observancia del Derecho $^{14}$.

En la actual coyuntura filosófica y filosófico-jurídica, abiertas al reconocimiento de la competencia práctica de la razón para establecer pautas éticas fundamentadoras de la convivencia social justa, la enseñanza y el ejemplo de los clásicos iusnaturalistas hispanos puede representar un provechoso estímulo. No en vano las reservas de Michel Villey frente a los escolásticos españoles tienen como uno de sus leitmotiven reprochables la intencionalidad práctica y coyuntural de sus doctrinas. La Summa de Tomás de Aquino responde, según Villey, a una concepción básicamente especulativa dirigida sólo al conocimiento. Por contra, Vitoria, Soto, Molina, Suárez o Vázquez se hallan especialmente interesados en la dimensión práctica de sus tesis. En lugar de cultivar el puro saber teórico, los clásicos españoles desean la «victoria de la moral cristiana» influyendo en la conciencia de los reyes, de sus funcionarios y de la comunidad de fieles; dirigiendo la opinión pública en temas como la Colonización americana, la política internacional o el gobierno de la Iglesia $^{15}$. Ese rasgo que para

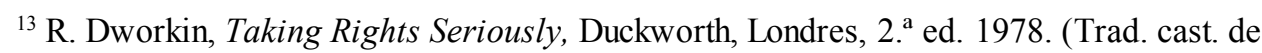
M. Guastavino, con Prólogo de A. Calsamiglia, Los derechos en serio, Ariel, Barcelona, 1984); id., AMatter of Principle, Harvard University Press, Cambridge (Mass.) y Londres, 1985; Law's Empire, Fontana, Londres, 1986.

${ }^{14}$ N. MacCormicky O. Weinberger, An Institutional Theory of Law, Reidel, Dordrecht, 1986. Del capítulo XI de esta obra sobre Los límites de la racionalidad en el razonamiento jurídico, existe trad. cast. de M. Atienza y J. Ruiz Manero incluida en el vol. a cargo de J. Betegón y J. R. Páramo, Derecho y Moral. Ensayos analíticos, Ariel, Barcelona, 1990, pp. 9 ss.

${ }^{15}$ M. Villey, La formation de la pensée juridique moderne, Montschrestien, Paris, 1968, pp. 353 ss.; id., «La promotion de la loi et du droit subjectif dans la Seconde Scolastique», en obra col. a cargo de Paolo Grossi, La Seconda Scolastica nella formazione del Diritto privato moderno (Atti del Incontro di studio, Firenze, 16-19 octubre 1972), Giuffrè, Milán, 1973, pp. 60-61; id., 
Iglesia $^{16}$. Ese rasgo que para Michel Villey era motivo de reproche ha sido valorado, en un reciente estudio de Rainer Specht, como la principal aportación histórica del iusnaturalismo español. La enseñanza de los clásicos hispanos: «Constituye -en palabras de Specht- un punto culminante de la Filosofía práctica formulada en términos de moral Science, y se cuenta entre las construcciones más impresionantes que ha forjado nuestra civilización: una Filosofía práctica que abarca toda la realidad. Que haya sido olvidado por nuestra conciencia cultural, a veces poco cuidadosa en la conservación de los fenómenos, es una de las razones que impiden hoy a la opinión pública, comprender a Europa como unidad cultural» ${ }^{17}$.

Un somero repaso a los tratados De legibus y De iustititia et iure, títulos preferentemente utilizados por los clásicos españoles para rotular sus obras, permite advertir desde sus primeras páginas la inequívoca orientación práctica que los informa. Así, lo expresa Luis de Molina al considerar como objeto de su reflexión el contribuir a fundamentar el juicio de cuanto fuera necesario para el gobierno de la Iglesia y la utilidad de la República cristiana $^{18}$. Francisco Suárez justifica el ocuparse de la ley, en su condición de teólogo, en la dependencia que de ésta tienen la rectitud de las costumbres, en la exigencia de examinar los motivos de la obediencia de las leyes, así como la aplicación de la filosofía moral para regir y gobernar las costumbres políticas de la cosa pública ${ }^{19}$. A un planteamiento análogo arriba Domingo Báñez, quien pone especial énfasis en justificar la necesidad de que los teólogos ejerciten su razón para abordar las principales cuestiones sobre la justicia y el Derecho, en cuanto que son materias que se dirigen a procurar la salud y el bienestar de los hombres. A su vez, los problemas que se derivan de la justicia y el Derecho no se pueden

«Saint-Thomas d'Aquin et Vitoria», en el vol., Las Casas et Vitoria, número monográfico de Le Supplément (Revue d'Ethique \& Théologie Morale), 1987, marzo, n. ${ }^{\circ} 160$, pp. 95 ss.

${ }^{16} \mathrm{M}$. Villey, La formation de la pensée juridique moderne, Montschrestien, Paris, 1968, pp. 353 ss.; id., «La promotion de la loi et du droit subjectif dans la Seconde Scolastique», en obra col. a cargo de Paolo Grossi, La Seconda Scolastica nella formazione del Diritto privato moderno (Atti del Incontro di studio, Firenze, 16-19 octubre 1972), Giuffrè, Milán, 1973, pp. 60-61; id., «Saint-Thomas d'Aquin et Vitoria», en el vol., Las Casas et Vitoria, número monográfico de Le Supplément (Revue d'Ethique \& Théologie Morale), 1987, marzo, n. ${ }^{\circ} 160$, pp. 95 ss.

${ }^{17}$ R. Specht, «Derecho natural español. Clasicismo y modernidad», trad. cast. de J. J. Gil Cremades, en Anuario de Filosofía del Derecho, 1990, vol. VII, p. 346. Este trabajo fue publicado en alemán enZeitschrift für philosophische Forschung, 1987, pp. 169 ss. Anteriormente había publicado el artículo, «Zur Kontroverse von Suarez und Vasquez über den Grund der Verbindlichkeit des Naturrechts», en Archiv für Rechis-und Sozialphilosophie, 1959, n. ${ }^{\circ}$ XIV, pp. 235 ss.

${ }^{18}$ L. de Molina, De iustititia et iure, I, 1.

${ }^{19}$ F. Suárez, De legibus, Proemium. 
comprender adecuadamente si no se deducen de la Filosofía las razones de las leyes humanas ${ }^{20}$.

¿Cuál puede ser la contribución actual de las doctrinas iusnaturalistas clásicas hispanas en orden a la relevancia jurídica y política de la racionalidad práctica? Rainer Specht ha resumido la aportación histórica del iusnaturalismo clásico español en tres postulados básicos: 1) Que existen principios prepositivos de justicia, que los cristianos fundamentan en un Dios que manda, prohíbe y exige responsabilidades por su observancia en el plano social y político; 2) Que la aplicación del Derecho no debe vincularse a la valoración de las personas o los grupos (como se demuestra en De indis); 3) Que el Derecho natural y el positivo se basan en la razón. La proyección de estas tesis al presente entraña, en función de cada una de ellas, consideraciones diferenciadas. Respecto a la primera, acepta que el Derecho se halle fundado en algo que le «precede», pero en las sociedades pluralistas actuales en las que se debe fundamentar el orden jurídico al margen de una determinada moral y de una determinada fe, para que todos los ciudadanos puedan reconocerlo como justo al margen de sus convicciones, tal fundamento no puede reposar en un determinado credo religioso. La segunda, ha hallado eco en los principios que hoy garantizan la imparcialidad del proceso: «audiatur et altera pars», "nemo iudex in propia causa» o «tratar igual lo igual». El fundamento racional del orden jurídico, tercera de las premisas de la Escuela española, habría sido reelaborada por el iusnaturalismo clásico alemán que concibe la racionalidad como libertad. La teoría alemana del Estado hará coincidir las ideas de Derecho y razón. Por eso, la doctrina de los iusnaturalistas clásicos hispanos sigue siendo familiar a la teoría jurídica y política del presente, que es una teoría de la acción racional. No obstante, conceptos tales como los de «naturaleza», «razón» y «res publica» han variado notablemente en los últimos cuatrocientos años. De ahí que ahora la razón deba servirse de orientaciones históricas y sociales; y que lo que es recto no lo pueda fijar una razón abstracta, sino una razón práctica que se mueve en contextos históricos determinados y se dirige a fines concretos. Como conclusión Specht propone que para que el «obrar racionalmente», postulado nuclear del iusnaturalismo clásico español, sea compatible con la teoría de la acción propia del Derecho moderno debería traducirse a estos términos: «obrar de acuerdo con el problema objetivo y conforme a orientaciones o referencias históricas, racionalmente controladas» ${ }^{21}$.

${ }^{20}$ D. Báñez, De iure et iustititia decisiones, Proemium.

${ }^{21}$ R. Specht, «Derecho natural español. Clasicismo y modernidad», cit., pp. 352-354. 
Rainer Specht, cuyo planteamiento me parece muy sugerente, no aclara qué es lo que entiende por el control racional de la acción. Este punto se halla en el centro de las actuales concepciones dialógicas. Como punto de partida estas tesis suponen un rechazo de las tesis nocognitivistas (escepticismo, relativismo, irracionalismo) en el sentido en que defienden la competencia de la razón práctica para fundamentar las normas y juicios morales. Desde sus premisas, en concreto desde las de Jürgen Habermas, el control racional de la acción tiene como principio la universalización, como método el procedimiento y como fin el consenso. La racionalidad de la acción exige que la norma moral que la acción cumple satisfaga el principio de universalización, es decir, pueda encontrar un reconocimiento general en su ámbito de aplicación. Frente al modelo de racionalidad metafísica que informa la teoría clásica del Derecho natural y que concibe la razón en función de contenidos axiológicos materiales (Dios, la Naturaleza), a partir del Derecho natural moderno, a través de Rousseau y Kant, se propugnará un método formal. Cuando «las razones últimas han dejado de ser plausibles, son las condiciones formales de la justificación las que cobran fuerza legítimamente por sí mismas. Los procedimientos y las premisas del acuerdo racional se elevan a la categoría del principio». El contractualismo desde Hobbes y Locke hasta John Rawls tendrá como objetivo «especificar las condiciones desde las que un acuerdo ha de expresar el común interés de todos los implicados (y, por ende, puede pasar como racional) $\rangle^{22}$. Mientras que en las teorías de signo trascendentalista, desde Kant a Apel, esas condiciones aparecen como presupuestos generales y necesarios de la formación racional de la voluntad, en un sujeto o en una comunidad ideal de comunicación. En ambas tradiciones esas condiciones formales que suplen a las razones últimas como factores de legitimación tiene como fin el consenso. Porque, en definitiva, «la cuestión fundamental de la filosofía práctica, una cuestión que en los tiempos modernos ha vuelto a ser acogida reflexivamente, en cuanto pregunta por los procedimientos y las premisas desde los que las justificaciones pueden tener un poder

${ }^{22}$ J. Habermas, La reconstrucción del materialismo histórico, trad. cast. de J. Nicolás Muñiz y R. García Cotarelo, Taurus, Madrid, 1981, p. 250. Vid. también sus trabajos: «Ueber Moralität und Sittlichkeit-Was macht eine Lebensform "rational"?», en el vol. a cargo de H. Schnädelbach, Rationalität, Suhrkamp, Frankfurt a.M., 1984, pp. 220 ss., id., «Moralität und Sittlichkeit. Treffen Hegels Einwände gegen Kant auch auf die Diskursethik zu?», en el vol. col. a cargo de W. Kuhlmann, Moralität und Sittlichkeit. Das Problem Hegels und die Diskursethik, Suhrkamp, Frankfurt a.M., 1986, pp. 16 ss. Cfr. mi libro, Derechos humanos, Estado de Derecho y Constitución, Tecnos, Madrid, 4. ${ }^{a}$ ed., 1991, pp. 163 ss. 
generador de consenso... Este es el punto de convergencia al que parecen tender hoy los intentos de una renovación de la filosofía práctica» ${ }^{23}$.

Los clásicos iusnaturalistas españoles fueron en la historia el eslabón entre el Derecho natural clásico y el moderno. Ello se refleja en su concepción de la racionalidad práctica que, como toda doctrina de transición, presenta rasgos ambivalentes. De una parte, siguen fieles a una fundamentación metafísica del orden jurídico y a unas «razones últimas» de tipo ontológico que conforman el sustrato axiológico material de sus construcciones. Pero, como contrapunto, llevan hasta sus últimas consecuencias el postulado tomista de la autonomía del orden humano regido por la racionalidad natural, respecto al orden trascendente de la fe y de la gracia. A los clásicos españoles les incumbe, por eso, un papel decisivo en el proceso de secularización del iusnaturalismo teológico medieval que condujo a la Escuela del Derecho Natural racionalista ${ }^{24}$. Tampoco carece de interés, en este aspecto, recordar que uno de los argumentos que arguyen los críticos de la Escuela española es su pretendido abandono del objetivismo ontológico en función de un subjetivismo que preanuncia la modernidad ${ }^{25}$.

Suelen soslayarse las aportaciones del iusnaturalismo clásico hispano a la actitud metódica procedimentalista y, pese a ello, su contribución puede juzgarse de interés en distintas esferas ${ }^{26}$. La Escuela española anticipó la formación del contractualismo moderno a través de sus teorías pactistas (baste recordar la célebre distinción suareciana entre el contrato de asociación pactum unionis y el contrato político pactum subjectionis ${ }^{27}$ ). Además, sus obras representan un continuo ejercicio de la teoría de la argumentación

${ }^{23}$ Ibid., p. 271.

${ }^{24}$ Cfr. sobre ello obra de Pierre Mesnard, L'essor de la philosophie politique au XVIe siècle, Vrin, París, 3. ${ }^{a}$ ed., 1969, pp. 466 ss;. así como las contribuciones recientes debidas a Franco Todescan, Lex, natura, beatitudo. Ill problema della legge nella Scolastica spagnola del sec. XVI, Cedam, Padova, 1973, pp. 53 ss.; id., Le radici teologiche del giusnaturalismo laico, Giuffrè, Milán, 1983, pp. 9 ss.

${ }^{25}$ Trato de ello en mi libro El iusnaturalismo clásico español en el Quinto centenario, en curso de publicación.

${ }^{26}$ Resulta sintomático que al estudiar las concepciones iusnaturalistas actuales sobre la argumentación y los principios procedimentales, Günter Ellscheid, prescinda del precedente de la Escuela española en su trabajo «Das Naturrechtsproblem. Eine systematische Orientierung», en el vol. a cargo de A. Kaufmann y W. Hassemer, Einführung in Rechtsphilosophie und Rechtstheorie der Gegenwart, Müller, Heidelberg, 1985, pp. 142 ss. y 157 ss. Tampoco Theodor Viehweg en su conocida obra Topik und Jurisprudenz, cit., Juan-Antonio García Amado en sus Teorías de la tópica jurídica, Civitas, Madrid, 1988, ni M. Atienza en su libro sobre Las razones del Derecho, cit., aluden a los clásicos hispanos.

${ }^{27}$ F. Suárez, De legibus, III,4,1.2. 
y de racionalidad discursiva. En ocasiones, la preocupación didáctica por establecer los argumentos en pro y en contra de las distintas cuestiones abordadas en los tratados De legibus y De iustititia et iure, es causa de una cierta rigidez formal de su método expositivo. Otras veces, los procedimientos discursivos se formulan de manera más viva y directa. El ejemplo de la presentación de Francisco de Vitoria en De Indis, sobre los títulos legítimos e ilegítimos justificadores de la presencia española en América, o las propias controversias sobre ese mismo tema de Valladolid entre Bartolomé de las Casas y Juan Ginés de Sepúlveda, constituyen una palpitante exposición dialógica de argumentos, de distinto peso lógico y moral, tendentes a suscitar consenso (por lo demás, harto difícil) sobre el problema abordado.

Resta por aludir a la exigencia, hoy presente en casi todas las tentativas antes apuntadas de proyectar la razón práctica al Derecho, de operar con consciencia histórica. La racionalidad práctica no puede actuar al margen de esas «orientaciones o referencias históricas» a las que aludía Specht; de ser sabedora de que sus principios o reglas sobre la ordenación justa del orden social no pueden abstraerse de contextualización. Incluso quienes, como es el caso de José Delgado Pinto, abogan en favor de una situación ideal de discusión racional capaz de «enunciar no sólo fórmulas vacías, sino verdaderos principios materiales de justicia universalmente válidos», supeditan tales principios al «contraste racional» y los circunscriben «a los problemas concretos que plantea la convivencia en cada sociedad histórica» ${ }^{28}$.

Es sabido que una de las críticas más penetrantes esgrimidas contra el iusnaturalismo clásico y moderno ha sido la de su ahistoricismo. La cultura filosófica y jurídica de nuestros días no acepta la existencia de un orden objetivo integrado por postulados universales, absolutos e inmutables de los que la razón pudiera extraer, de una vez por todas, los principios ordenadores de las sociedades justas ${ }^{29}$. Ésta puede ser una importante cortapisa al

${ }^{28}$ J. Delgado Pinto, De nuevo sobre el problema del Derecho natural, Ediciones Universidad de Salamanca, 1982, p. 33.

${ }^{29}$ Frente al iusnaturalismo dogmático basado en un objetivismo ontológico, estimo más acorde con las exigencias filosóficas y jurídicas del presente un iusnaturalismo crítico, que propugna una racionalidad práctica intersubjetiva y concibe la naturaleza como el conjunto de necesidades antropológicas que enmarcan el devenir histórico de las sociedades. Cfr. mis libros: Lecciones de Filosofía del Derecho. Presupuestos para una filosofía de experiencia jurídica, Minerva, Sevilla,

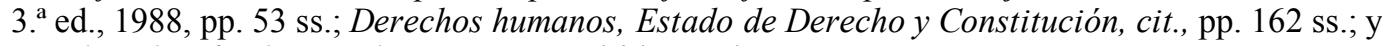
Los derechos fundamentales, Tecnos, Madrid, 4. ${ }^{a}$ ed., 1991, pp. 128 ss. 
influjo actual de las ideas sobre la racionalidad práctica de los clásicos iusnaturalistas españoles. Pero no sería lícito olvidar que, precisamente, uno de los aspectos más encomiados de la Escuela española, en relación con los excesos «ucrónicos» de la Escuela racionalista del Derecho natural, ha sido el de su sensibilidad hacia lo concreto y su apertura a lo histórico. En los inicios de nuestro siglo Joseph Kohler, en un estudio que ha devenido indispensable, valoró la flexibilidad de la concepción iusnaturalista de los clásicos españoles. Para ellos el Derecho natural no es un código rígido e inmutable sino que, respetando el carácter universal e incondicionado de los primeros principios, admiten la adaptación de sus derivaciones a las circunstancias históricas. Los magni hispani supieron aplicar los principios generales del Derecho natural aristotélico-tomista a las exigencias concretas de su tiempo, ofreciendo soluciones a numerosos conflictos éticos, jurídicos y políticos. Su método constituye, por eso -en opinión de Kohler-, un valioso ejercicio de racionalidad práctica que puede ser útil a los juristas, en cuanto que su labor suele tener por objeto la aplicación de normas generales a la peculiaridad de los casos planteados ${ }^{30}$.

He invocado, en el inicio de este comentario y para justificar su tematización, las concomitancias existentes entre nuestra época y la que vivieron los clásicos españoles. Esas analogías no bastan para difuminar una distancia de cuatro siglos. Lo mismo ocurre con las construcciones teóricas de aquel período. Su conocimiento, con vistas a la conformación de nuestros actuales esquemas de racionalidad práctica resulta útil, casi diría que inevitable, si deseamos actuar con consciencia diacrónica y aprovechar la experiencia de sus aciertos y fallos. Pero lo que no es posible es trasladar sin más, como en alguna ocasión se ha pretendido, aquellos esquemas al presente. El ejercicio actual de la racionalidad práctica puede y debe contar con las aportaciones de otras tradiciones culturales, así como con los datos últimos de la evolución del pensamiento filosófico y científico. La racionalidad práctica no puede imaginarse al margen de la criba racional, o sea, autocrítica que depure sus propios métodos y sistemas operativos.

${ }^{30}$ J. Kohler, «Die spanischen Naturrechtslehrer des 16. und 17. Jahrhunderts», en Archiv für Rechts-und Wirtschaftsphilosophie, 1916-17, pp. 235 ss. 
DOXA-12 (1992) 